\title{
Modeling conditional volatility by incorporating non-regular trading hours into the APARCH model
}

\author{
Breno Valente Fontes Araújo ${ }^{1}$ \\ (D) https://orcid.org/0000-0002-8855-5830 \\ Email: brenovfa@gmail.com \\ Marcos Antônio de Camargos ${ }^{1,2}$ \\ (D) https://orcid.org/0000-0002-3456-8249 \\ Email: marcosac@face.ufmg.br \\ Frank Magalhães de Pinho1, 2 \\ (D) https://orcid.org/0000-0002-5063-3389 \\ Email: frank.pinho@ibmec.edu.br
}

\author{
Universidade Federal de Minas Gerais, Faculdade de Ciências Econômicas, Centro de Pós-Graduação e Pesquisas em Administração, Belo \\ Horizonte, MG, Brazil \\ Ibmec BH, Departamento de Administração, Belo Horizonte, MG, Brazil
}

Received on 01.08.2018 - Desk acceptance on 01.23.2018 - $2^{\text {nd }}$ version approved on 06.21.2018 - Ahead of print on 11.01.2018

Associate Editor: Fernanda Finotti Cordeiro Perobelli

\section{ABSTRACT}

This study aims to evaluate how the after-market and pre-opening periods affect the estimation of conditional volatility one day ahead. Volatility features quite a lot in Finance studies because it is a fundamental parameter in derivatives pricing, the efficient allocation of portfolios, and risk management. The results are relevant for investment agents to be able to refine volatility forecasting models and achieve better results in derivatives pricing, risk management, and portfolio optimization. We used the asymmetric power autoregressive conditional heteroscedasticity (APARCH) model, incorporating the aftermarket, pre-opening, and total overnight periods to assess whether they contain important information for modeling volatility. We analyzed the 20 stocks of Brazilian companies listed on the São Paulo Stock, Commodities, and Futures Exchange (BM\&FBovespa) and also belonging to the BR Titans 20 with ADRs listed on the New York Stock Exchange and the Nasdaq. The results were evaluated in-sample using the corrected Akaike information criterion (AICc) and the statistical significance of the coefficients, and out-of-sample using root mean squared error (RMSE), mean absolut percentage error (MAPE), the $\mathrm{R}^{2}$ of the Mincer-Zarnowitz regression, and the Diebold Mariano test. The analysis does not enable it to be claimed which is the best model, because there is no unanimity among all the stocks; however, non-regular trading hours were shown to incorporate important information for most of the stocks. Furthermore, the models that incorporated the pre-opening period generally obtained superior results to the models that incorporated the after-market period, demonstrating that this period contains important information for forecasting conditional volatility.

Keywords: conditional and realized volatility, APARCH model, intraday data, after-market, pre-opening.

\section{Correspondence address}

Breno Valente Fontes Araujo

Universidade Federal de Minas Gerais, Faculdade de Ciências Econômicas, Centro de Pós-Graduação e Pesquisas em Administração

Avenida Presidente Antônio Carlos, 6627, Sala 4012 - CEP: 31270-901

Pampulha - Belo Horizonte - MG - Brazil

*Paper presented at the XLI Meeting of the National Association of Post-Graduation and Research in Business Administration, São Paulo, SP, Brazil, October 2017. 


\section{INTRODUCTION}

Various studies in Brazil and abroad have used daily data to forecast conditional volatility one day ahead. In Brazil, most of these studies have been developed in the last 20 years, indicating the good performance of the models belonging to the ARCH (autoregressive conditional heteroskedasticity) family in forecasting volatility (Cavaleri \& Ribeiro, 2011; Ceretta \& Costa, 2001; Gaio, Pessanha, Oliveira \& de Ázara, 2007; Galdi \& Pereira, 2007; Silva, C. A. G., 2009). However, most of the studies that seek to model the conditional volatility of stocks or indices ignore the variation that occurs between the opening period of one day and the close of the previous day, also known as the overnight period. We found some studies in Brazil that have sought to analyze the significance of the information found in the overnight period (Accioly \& Mendes, 2015; Souza, 2004), while finding various studies from abroad that discuss the issue (Barclay \& Hendershott, 2004; Chen, Yu \& Zivot, 2012; Gallo \& Pacini, 1998; Martens, 2002; Taylor, 2007).

Article 5 of Normative Instruction n. 358 of the Brazilian Securities and Exchange Commission (CVM, 2002) determines that the disclosure of relevant acts or facts should occur, whenever possible, before the opening or after the closing of the stock exchange trading session. Thus, relevant information is probably disclosed in nonregular trading hours and reflected in the after-market or in the opening price of stocks. Such information tends to influence the market dynamic during regular trading hours, directly affecting the volatility of the stocks.

Nicolau (2012) indicates that the intense arrival of information tends to increase the volatility of returns. The author suggests inserting explanatory variables into the conditional volatility forecasting model when these variables incorporate information that affects volatility. Zivot (2009) highlights studies that have identified explanatory variables that, when incorporated into the GARCH-family models, improve forecasting results, such as volume traded, releases of macroeconomic data, overnight return, after-hours volatility, implicit volatility in options prices, and realized volatility.

With the advance of technology and the more frequent availability of data, studies have emerged with new ways of modeling and forecasting volatility. Recent papers, both in Brazil and abroad, have used high-frequency intraday data to calculate realized volatility. This variable is used as an "observable" measure of the volatility of a day, which provides a more effective out-of-sample analysis than other measures used, such as the squared return for the day (Andersen \& Bollerslev, 1998). In addition, intraday data enable price behavior in non-regular trading hours to be analyzed in a fractional form, since there is specific information from the after-market period and from the pre-opening period.

It is thus believed that, during the overnight period, relevant facts occur for modeling the conditional volatility of a stock and that this information may be contained both in the after-market and in the pre-opening periods, and reflected in the opening price. Therefore, the aim of this paper is to evaluate how the after-market, preopening, and total overnight periods affect the conditional volatility estimation for the Brazilian companies listed on the São Paulo Stock, Commodities, and Futures Exchange (BM\&FBovespa) and belonging to the Dow Jones Brazil Titans 20 ADR Index (BR Titans 20).

This study differs from the rest especially by dividing overnight return into sub periods, as is done by Chen et al. (2012). However, due to the peculiarities of the Brazilian market, the overnight period was divided into two sub periods, instead of three: the after-market and the pre-opening periods. For this, the APARCH model was used, incorporating the variation of the after-market period in relation to the close of the trading session and the variation of the opening price in relation to the closing price of the after-market period of the previous day (preopening period variation), as well as the total overnight variation (variation between opening price and closing price of the regular trading session of the previous day) as explanatory variables of the model.

The study therefore aims to contribute to the literature in three ways: (i) by presenting an analysis of the overnight period, which has still scarcely been studied in Brazil; (ii) by using sub periods of the non-regular trading hours as explanatory variables for modeling conditional volatility; (iii) by carrying out an out-of-sample analysis, using realized volatility as a parameter, calculated based on intraday data.

The article has the following structure: after this introduction, section 2 presents the theoretical framework that supports the empirical research. The methodology and the results are presented in sections 3 and 4, respectively, and the paper concludes with the final remarks in section 5 , followed by the references. 


\section{THEORETICAL FRAMEWORK}

\subsection{Conditional Volatility - ARCH-Family Models}

The series of returns on financial assets present, as a characteristic property, serial non-correlation, but instead the existence of dependency in their structure. In other words, past returns do not influence present return, but volatility is correlated with past returns or with "innovations" (residuals) around the mean equation (Tsay, 2010). In his seminal paper, Engle (1982) proposed the ARCH model, in which conditional variance can be modeled using a quadratic function. The estimators of the parameters of the ARCH-family model, as well as the others from the family shown below, can be obtained by the conditional maximum likelihood estimator (Engle, 1982; Tsay, 2010).

In most cases, the conditional volatility equation requires a high-order (many parameters) ARCH model in order to be adequately described (Tsay, 2010). This can generate estimation problems during the convergence of the optimization algorithm (Nicolau, 2012). To overcome this limitation of the ARCH model, Bollerslev (1986) proposed an alternative one for modeling the "innovations" (residuals) of a return on assets series, better known as the GARCH model.

Over the years, several models have been developed with the aim of incorporating different behaviors of financial data series: IGARCH, EGARCH, GJR-GARCH, etc. In this study, we chose to use the APARCH model due to the fact that it is capable of behaving like the other seven models from the ARCH family.

The asymmetric power autoregressive conditional heteroskedasticity (APARCH) model, presented by Ding, Granger, and Engle (1993), emerged from the question that conditional variation does not necessarily follow a quadratic or linear function. The model thus offers a general way in which the strength of the conditional variance equation is also estimated, as well as the traditional parameters, such as alpha and beta. According to the authors, the APARCH model can be represented by equation 1 :

$$
\sigma_{t}^{\delta}=\omega+\sum_{i=1}^{q} \alpha_{i}\left(\left|\epsilon_{t-i}\right|-\gamma_{i} \epsilon_{t-i}\right)^{\delta}+\sum_{j=1}^{p} \beta_{j} \sigma_{t-j}^{\delta}
$$

in which $\omega, \alpha_{i}, \gamma_{i}, \delta$, and $\beta_{j}$ are parameters to be estimated by the model. As in the other models, $\omega$ is the intercept of the model, which portrays the average level of conditional variance; that is, the unconditional variance can be considered. $\alpha_{i}$ and $\beta_{j}$, as presented above, represent how much the shock (innovation) affects the conditional variance and how much the lagged conditional variance itself persists in the current period, respectively. $\gamma_{i}$, as in the GJR-GARCH model, captures the asymmetric response of the conditional variance to positive and negative shocks, also known as the leverage effect, that is, if positive and negative shocks affect the conditional variance one period ahead differently. If $\gamma_{i}$ is statistically significant and positive, it indicates the existence of the leverage effect; that is, negative shocks have a greater impact over conditional variance one day ahead. If $\gamma_{i}$ is statistically significant and negative, it indicates that positive shocks have a greater impact over conditional variance. Finally, $\delta$ enables other strengths for the conditional variance equation to be estimated by means of a Box-Cox transformation of $\sigma_{t}$.
The APARCH model can be considered one of the most promising of the ARCH family, since it is able to encompass at least seven models from this family, as can be seen in the following special cases: $\mathrm{ARCH}(\delta=$ $2, \gamma_{i}=0$, and $\left.\beta_{j}=0\right)$, GARCH $\left(\delta=2, \gamma_{i}=0\right)$, non-linear $\operatorname{ARCH}\left(=0\right.$ and $\left.\beta_{j}=0\right)$, Taylor/Schwertz's GARCH $(\delta=$ $\left.1, \gamma_{i}=0\right)$, TARCH $\left(\delta=1\right.$ and $\left.\beta_{j}=0\right), \log -\operatorname{ARCH}(\delta \rightarrow 0)$, and GJR-GARCH $(\delta=2)$. Thus, we chose the APARCH model due to the fact that this study does not aim to evaluate the different models, but rather the impact of the exogenous variables.

\subsection{Realized Volatility}

The great difficulty in evaluating the validity of the volatility estimation derives from the fact that it is not observable. A technique is thus needed for measuring daily volatility a posteriori to evaluate the forecasting power of the models. Andersen and Bollerslev (1998) indicate that the squared return for the day, despite not being very effective, could be used as a proxy for daily volatility, as a 
comparison parameter for the out-of-sample analysis of the models. Studies such as those by Cumby, Figlewski, and Hasbrouck (1993), Jorion (1995), and Figlewski (1997) found that the GARCH models present poor results for volatility estimations, not because of deficiencies in the model, but due to the fact that the squared return for a day is not a good proxy to use for the daily volatility of a stock, given that the price of a stock can reach high and low values in relation to the opening price and later return to the opening price, the volatility thus being equal to 0 .

To overcome this problem with regard to determining the variable to be used as a proxy for daily volatility, Andersen and Bollerslev (1998) presented the concept of realized volatility, or perceived volatility. This measure can be estimated by the sum of the squared returns from the intraday (high frequency) data. The authors showed that this measure is much more reliable for use as a proxy of daily volatility, since it more closely matches the integrated volatility of the day. In our study, we used this measure as a proxy for daily volatility to be compared with the conditional volatility estimated by the models.

Realized volatility can be described in the following simplified way, as indicated by Andersen, Bollerslev, Diebold, and Ebens (2001a), Andersen, Bollerslev, Diebold, and Labys (2001b), and Bollerslev and Wright (2001):

$$
\begin{gathered}
r_{t, i}=P_{t, i}-P_{t, i-1} \\
R V_{t}^{2}=\sum_{i=1}^{n} r_{t, i}^{2}
\end{gathered}
$$

in which $P$ is the logarithm of the price, $i$ is the fraction of the regular trading session, in this case every 15 minutes, $r_{t, i}$ is the log-return of the $\mathrm{i}$-th 15-minute interval of the day, $n$ is the number of observations for each day, and $R V^{2}$ is the realized variance for the day.
Andersen, Bollerslev, Diebold, and Labys (2001c) indicated that the greater the frequency of the intraday data, the closer the realized volatility is to the integrated volatility, which can be considered effectively realized over a particular time horizon. However, the authors indicated that the use of "continuous" data to estimate realized volatility can cause major biases, due to the existence of market microstructure frictions, such as bid-ask bounce and low trading frequency, among others.

Andersen et al. (2001c) thus propose sampling in 5-minute intervals to ease such microstructure problems. There is a debate in the literature about which is the best window for calculating realized volatility. The empirical studies in the literature indicate that the optimal frequency for the calculation lies between 5 and 25 minutes (Mota \& Fernandes, 2004). Oomen (2001) presents 25-minute intervals as the optimal frequency. Giot and Laurent (2004) found an optimal frequency of 15 minutes for their study. We chose to use the 15-minute frequency, due to the availability of data and the use of the same frequency in numerous Brazilian studies (Milach, 2010; Moreira \& Lemgruber, 2004; Mota \& Fernandes, 2004; Reis, 2011; Silva, J. C., 2002).

\subsection{Functioning of the BM\&FBovespa and the Overnight Period}

As observed in Table 1, the BM\&FBovespa has two stock-trading periods: (i) the regular trading session, which occurs between 10am and 5pm, and (ii) the aftermarket period, which occurs between $5.30 \mathrm{pm}$ and $6 \mathrm{pm}$ and is the only way of trading after the close of the session, thus representing one of the means for variation between closing and opening values, and warranting a study of the functioning and its particularities. Besides the aftermarket period, the pre-opening period also contributes directly to the variation between the closing price of the previous day and the opening price of the following day, given that, despite no trading occurring, orders have already been placed, thus affecting the opening price.

Table 1

\begin{tabular}{|c|c|c|c|c|c|c|c|c|c|c|c|c|}
\hline \multirow{3}{*}{ Market } & \multirow{2}{*}{\multicolumn{2}{|c|}{ Canceling of orders }} & \multirow{2}{*}{\multicolumn{2}{|c|}{ Pre-opening }} & \multirow{2}{*}{\multicolumn{2}{|c|}{ Trading }} & \multirow{2}{*}{\multicolumn{2}{|c|}{ Closing call }} & \multicolumn{4}{|c|}{ After-market } \\
\hline & & & & & & & & & \multicolumn{2}{|c|}{ Canceling of orders } & \multicolumn{2}{|c|}{ Trading } \\
\hline & Start & End & Start & End & Start & End & Start & End & Start & End & Start & End \\
\hline $\begin{array}{c}\text { Spot } \\
\text { market }\end{array}$ & 9:30am & 9:45am & 9:45am & 10am & 10am & 4:55pm & $4: 55 p m$ & $5 \mathrm{pm}$ & $5: 25 \mathrm{pm}$ & 5:30pm & 5:30pm & $6 p m$ \\
\hline
\end{tabular}

Functioning of the São Paulo Stock, Commodities, and Futures Exchange (BM\&FBovespa)

Source: Adapted from BM\&FBovespa (2014). 
The stipulated limit for variations in a stock in the after period of $2 \%$ above or below the closing price restricts the analysis of the study, since there can be days on which the after-market variation reaches $2 \%$ and does not exceed this due to impossibility, thus not representing the reality of the buy and sell orders. To overcome this situation, we verified the number of times in which the after-market period variation approached $2 \%$. We found that this did not occur for any company in more than $1 \%$ of the observations. We thus decided not to evaluate this fact in the estimated models, due to the low number of relevant observations.

The overnight period, that is, the period between the close of one day and the opening of the next, has been the focus of many studies over the years. Most of the studies evaluate how the information from this period affects the behavior of the market in regular trading hours and the volatility of stocks and indices, as is observed in Table 2 .

\section{Table 2}

Empirical evidence analyzing the overnight period in the Brazilian and international literature

\begin{tabular}{|c|c|c|}
\hline Author (year) & Objective & Conclusion \\
\hline $\begin{array}{l}\text { Accioly and Mendes } \\
\qquad(2015)\end{array}$ & $\begin{array}{l}\text { To evaluate the insertion of realized volatility as } \\
\text { an exogenous variable in the GARCH model and } \\
\text { incorporating the squared return for the overnight period. }\end{array}$ & $\begin{array}{l}\text { They concluded that the return for the overnight period } \\
\text { has explanatory power in some cases, but presented less } \\
\text { power than the one-factor approach presented by them. }\end{array}$ \\
\hline $\begin{array}{l}\text { Chen et al. } \\
\text { (2012) }\end{array}$ & $\begin{array}{l}\text { To evaluate the traditional GARCH model in forecasting } \\
\text { conditional volatility, based on intraday data, for a } \\
\text { model that also covers non-regular trading hours } \\
\text { for the } 30 \text { most liquid stocks on the Nasdaq. }\end{array}$ & $\begin{array}{l}\text { The post-closure and overnight variation present } \\
\text { little explanation of conditional volatility, while } \\
\text { the pre-opening period presents statistical } \\
\text { significance in relation to this variable. }\end{array}$ \\
\hline $\begin{array}{l}\text { Taylor } \\
(2007)\end{array}$ & $\begin{array}{l}\text { To evaluate the economic value of the overnight period } \\
\text { information for agents that work with risk management. }\end{array}$ & $\begin{array}{l}\text { The overnight information has a significant impact over } \\
\text { the conditional volatility of the assets analyzed, thus } \\
\text { promoting more precise models for risk management. }\end{array}$ \\
\hline $\begin{array}{l}\text { Souza } \\
(2004)\end{array}$ & $\begin{array}{l}\text { To analyze whether incorporating the overnight } \\
\text { effect into the GARCH model leads to a reduction } \\
\text { in the persistence of volatility with daily data on the } \\
\text { eight most liquid stocks of the BM\&FBovespa. }\end{array}$ & $\begin{array}{l}\text { A reduction effect was detected in the persistence } \\
\text { of the volatility for these stocks. However, it was not } \\
\text { possible to reach a conclusion about the best estimation } \\
\text { model, due to the different results for each one. }\end{array}$ \\
\hline $\begin{array}{l}\text { Barclay and } \\
\text { Hendershott } \\
\quad(2003)\end{array}$ & $\begin{array}{l}\text { To evaluate how the information disclosed during the } 24 \\
\text { hours in a day affects quantity, price, and when trading } \\
\text { is carried out, with a focus on the after-market period. }\end{array}$ & $\begin{array}{l}\text { Prices are more efficient and more information is } \\
\text { revealed per hour during regular trading hours than } \\
\text { in the after-market period. However, the little trading } \\
\text { in the after-market period may reveal significant } \\
\text { explanations regarding the price of stocks. }\end{array}$ \\
\hline $\begin{array}{l}\text { Martens } \\
(2002)\end{array}$ & $\begin{array}{l}\text { To examine whether by including various } \\
\text { forms of after-hours volatility the GARCH } \\
\text { model improves volatility forecasts. }\end{array}$ & $\begin{array}{l}\text { They concluded that this inclusion does not present } \\
\text { a significant improvement for the model. }\end{array}$ \\
\hline $\begin{array}{l}\text { Gallo and Pacini } \\
\text { (1998) }\end{array}$ & $\begin{array}{l}\text { To evaluate whether the variations between the } \\
\text { opening price of one day and the closing price of } \\
\text { the previous day have explanatory power regarding } \\
\text { the conditional volatility of different indices. }\end{array}$ & $\begin{array}{l}\text { They detected that, when forecasting volatility out-of- } \\
\text { sample, by adding this variable the model presented } \\
\text { superior results to the traditional GARCH model. }\end{array}$ \\
\hline
\end{tabular}

BM\&FBovespa $=$ São Paulo Stock, Commodities, and Futures Exchange.

Source: Elaborated by the authors.

In addition to the evidence presented here, Barclay and Hendershott (2004) highlight that after the regular trading session, stocks tend to represent more private information than during trading hours, and that agents that trade in the after-market period tend to be more professional and represent institutions. The authors also indicated that the transactions carried out in the period after the regular session are only important when they present sufficient trading activities. In other words, it makes no sense to analyze stocks that present little variation outside the regular session, which also justifies us choosing our sample of Brazilian companies belonging to the BR Titans 20 index. 


\section{METHODOLOGY}

The sample analyzed is formed of companies listed on the BM\&FBovespa and belonging to the BR Titans 20 index, calculated since 2004 based on the Brazilian company ADRs that are most traded on the New York Stock Exchange and the Nasdaq, as presented in Table 3.

Table 3

Brazilian companies belonging to the Dow Jones Brazil Titans 20 ADR Index (BR Titans 20)

\begin{tabular}{|c|c|c|c|c|c|}
\hline Company name & Code & Company name & Code & Company name & Code \\
\hline Ambev S/A & ABEV3 & Copel & CPLE6 & Oi S/A & OIBR4 \\
\hline Banco Bradesco & BBDC4 & CSN & CSNA3 & Petrobras S/A & PETR4 \\
\hline Banco Santander & SANB11 & CPFL S/A & CPFE3 & Telefônica S/A & VIVT4 \\
\hline BRF S/A & BRFS3 & Embraer S/A & EMBR3 & Tim Participações & TIMP3 \\
\hline Pão de Açúcar & PCAR4 & Fibria Celulose S/A & FIBR3 & $\begin{array}{c}\text { Ultrapar } \\
\text { Participações S/A }\end{array}$ & UGPA3 \\
\hline Sabesp & SBSP3 & Gerdau S/A & GGBR4 & Vale S/A & VALE5 \\
\hline Cemig & CMIG4 & Itaú-Unibanco S/A & ITUB4 & & \\
\hline
\end{tabular}

Source: Elaborated by the authors.

The data used in this study are intraday, obtained with the help of a research group linked to a computing department of the same university as that of the authors. They are adjusted for dividends and other corporative events (inplits and splits) that affect the price directly without the need for trading, and were treated in a way that they contained information on the price of the stocks every 15 minutes for the regular trading hours and aftermarket period.

The analysis period ran from January $1^{\text {st }}$ of 2010 to March $20^{\text {th }}$ of 2015 for nine stocks, totaling around 1,290 daily observations, and until July $24^{\text {th }}$ of 2015 for the other 11 stocks, totaling 1,375 daily observations. This time difference derives from the availability of the data obtained. We chose this period as it considers moments of crisis in the financial system, such as the debt solvency crisis in Europe and the political problems associated with public debt in Brazil, enabling periods of high and low volatility to be incorporated.

Similarly to the window used by Chen et al. (2012), the out-of-sample period analyzed in this study was approximately one year (260 days). The in-sample analysis was carried out with all the other data from the sample, since, according to $\mathrm{Ng}$ and Lam (2006), in-sample windows with approximately a thousand observations minimize the impacts on the estimation of the coefficients of the GARCH-family models.

For the out-of-sample evaluation, that is, of the oneday-ahead conditional volatility forecast, we defined rolling recursive as the data analysis strategy; for every new conditional variance forecast, the model was estimated once more, contemplating the new observation. For example, to predict the volatility of period 1,001 , the 1,000 previous observations are used to estimate the model; to predict the volatility of period 1,002 , the 1,001 previous observations are used, and so on.

The exogenous variables evaluated and how they were calculated are shown below:

- After-market (AM) variation: the logarithmic variation of the after-market closing price in relation to the closing price of the regular trading session;

- Pre-opening period (OP) variation: the logarithmic variation of the opening price one day ahead in relation to the closing price of the after period of the previous day;

- Total overnight (OV) variation: the logarithmic variation of the opening price of one day in relation to the closing price of the regular trading session of the previous day.

As the interest of the analysis lies in the absolute variation of the values, that is, independent of whether the variation is positive or negative, the variations raised to the square were used. Therefore, four different models were analyzed for each stock: a traditional APARCH one and another three incorporating each one of the exogenous variables, as indicated in Table 4. 
Table 4

APARCH (asymmetric power autoregressive conditional heteroscedasticity) models evaluated

$\sigma_{t}^{\delta}=\omega+\sum_{i=1}^{q} \alpha_{i}\left(\left|\epsilon_{t-i}\right|-\gamma_{i} \epsilon_{t-i}\right)^{\delta}+\sum_{j=1}^{p} \beta_{j} \sigma_{t-j}^{\delta}$

$\sigma_{t}^{\delta}=\omega+\sum_{i=1}^{q} \alpha_{i}\left(\left|\epsilon_{t-i}\right|-\gamma_{i} \epsilon_{t-i}\right)^{\delta}+\sum_{j=1}^{p} \beta_{j} \sigma_{t-j}^{\delta}+\partial A M_{t-1}^{2}$

$\sigma_{t}^{\delta}=\omega+\sum_{i=1}^{q} \alpha_{i}\left(\left|\epsilon_{t-i}\right|-\gamma_{i} \epsilon_{t-i}\right)^{\delta}+\sum_{j=1}^{p} \beta_{j} \sigma_{t-j}^{\delta}+\partial O P_{t}^{2}$

$\sigma_{t}^{\delta}=\omega+\sum_{i=1}^{q} \alpha_{i}\left(\left|\epsilon_{t-i}\right|-\gamma_{i} \epsilon_{t-i}\right)^{\delta}+\sum_{j=1}^{p} \beta_{j} \sigma_{t-j}^{\delta}+\partial O V_{t}^{2}$

The variables are described in the text.

Source: Elaborated by the authors.

In order to refine the models and following the recommendation from Tsay (2010), each one of them was estimated until order 2 , that is, $(1,1),(1,2),(2,1)$, and $(2,2)$, so as to identify the one that best fits the series. Before the estimations, the test proposed by Ljung and Box (1978) was carried out to verify the autocorrelation in the daily log-returns series. An autoregressive model - ARMA $(1,1)$ was adjusted to the mean equation, in order to guarantee that the residuals (innovations) were independent and identically distributed (i.i.d.). Having done this, the ARCH test was carried out to prove the existence of heteroskedasticity. At this point, the conditional volatility models were estimated using the APRACH model.

Initially, the APRACH $(1,1)$ model was estimated for the different distributions of the "innovations" (residuals), in order to identify the one that best fits the data series. Subsequently, the different models were adjusted for the conditional volatility estimation, with and without the exogenous variables. The models that did not present satisfactory results in the tests for their fit were not evaluated, while the others were initially evaluated in-sample. Those that presented the best result in the in-sample analysis in each group were chosen for the out-of-sample analysis in order to identify those that presented the best results for forecasting volatility one day ahead.
For the estimation of the models, two different distributions of the residuals around the mean equation were considered: Student $t$ asymmetric and generalized (GED) asymmetric. The non-evaluation of a normal distribution was due to the fact that it is a particular case of the GED distribution. Similarly, the asymmetric distributions cover both possibilities, with and without asymmetry. In addition, one of the sterilized facts already proven in the finance literature is the asymmetric behavior of the data series, which suggests a better fit for these distributions. The Student $t$ asymmetric distribution was the most appropriate for all the log-returns series, but for the Vale stock, for which the GED asymmetric distribution was shown to be more adequate.

To check whether the models are well specified, the standardized "innovations" should form part of the sequence of random i.i.d. variables, in which the heteroskedasticity effect has been eliminated. As indicated by Tsay (2010), the Ljung-Box test was used to verify whether the standardized residuals (innovations) are i.i.d., proving that the equation for the mean is adequate, and the Lagrange multiplier (LM) or the Ljung-Box of the standardized residuals squared to test whether the ARCH effect was controlled, proving that the conditional variance equation is adequate. The calculation of the standardized "innovations" $\widetilde{\varepsilon_{t}}$, or standardized residuals, is carried out in the following way: 


$$
\widetilde{\varepsilon_{t}}=\frac{\varepsilon_{t}}{\sigma_{t}}
$$

For the in-sample analysis, we used the corrected Akaike (AICc) criterion, proposed by Akaike (1974), a function in which the quality of the adjusted model is penalized according to the number of estimated parameters. The equation for the AICc calculation is:

$$
A I C=-2 L+2 p
$$

in which $L$ represents the maximum value of the loglikelihood function of the model and $p$ is the number of estimated parameters.

Hurvich and Tsai (1993) proposed a correction in the AIC, called AICc, which can be calculated based on the following transformation:

$$
A I C c=A I C+\frac{2 p(p+1)}{n-p-1}
$$

in which $n$ would be the sampling size of the dataset used in the model estimation. The AICc penalizes the incorporation of parameters and, if the sample is very large, the AICc tends towards the traditional AIC. Burnham and Anderson (2004) recommend the use of the AICc instead of the AIC, especially in cases in which the number of observations is small. Therefore, the AICc will be used for the in-sample analysis and to determine the models that best fit the sample.

For both criteria, the lower the value, the better; that is, those that present the lowest value for the AICc will be chosen as the best. After verifying the models that best fit each data series, the best of each group were used for the estimation of conditional volatility one period ahead for the out-of-sample analysis.

In the out-of-sample analysis, three techniques were used: the Mincer and Zarnowitz (1969) regression, root mean squared error (RMSE), and mean absolute percentage error (MAPE). The idea of the Mincer-Zarnowitz (MZ) regression is simple: just regress the realized (observable) volatility according to the conditional volatility estimated by the models. The regression is formally described in the following way:

$$
\left(R V_{t+k}^{2}\right)^{1 / 2}=\alpha_{0}+\alpha_{1}\left(\sigma_{t+k \mid t}^{2}\right)^{1 / 2}+u_{t+k}
$$

in which $R V_{t+k}^{2}$ is the realized variance of day $\mathrm{t}+\mathrm{k}$ and $\sigma_{t+k \mid t}^{2}$ refers to the conditional variance estimated for day $\mathrm{t}+\mathrm{k}$ based on the information available on day $\mathrm{t}$. In the Mincer-Zarnowitz regression, if the conditional volatility is well estimated, $\alpha_{0}$ and $\alpha_{1}$ should be equal to 0 and 1 , respectively, with good statistical significance. However, these coefficients may suffer from the problem of variable measurement errors, making their interpretation difficult (Andersen \& Bollerslev, 1998). Nonetheless, the authors indicate that the $\mathrm{R}^{2}$ of the regression can be used to evaluate the measure used as expost volatility, in this case expressed by the realized volatility, explained by the conditional volatility.

Another evaluation metric used is the RMSE of the values estimated by the models in relation to the realized volatility for the day. The RMSE is used to indicate how distant, on average, the set of estimates is from the forecasted parameter:

$$
R M S E=\left[\frac{1}{T} \sum_{t=1}^{T}\left(R V_{t}^{2}-\sigma_{t}^{2}\right)^{2}\right]^{1 / 2}
$$

We also used the MAPE evaluation method that has the easy interpretation aspect as its main advantage since the scale is in percentage, being its main disadvantage the fact that if the realized value is very small or 0 , the MAPE value "explodes" or it is not possible to calculate.

$$
M A P E=\frac{1}{T} \sum_{t=1}^{T}\left|\frac{R V_{t}-\sigma_{t}}{R V_{t}}\right| .100
$$

Finally, the Diebold Mariano (1995) test was carried out to compare whether the forecasting errors, that is, the difference between the estimated and observed values of the alternative models, were statistically different from the traditional model.

The null hypothesis is that there is no statistical difference between the errors; that is, the models are, on average, equally precise. In this study, two scenarios were used as an alternative hypothesis: (i) the models are statistically different; and (ii) the alternative model is superior to the traditional model. We were thus able to evaluate not only whether there is statistical difference, but also whether the alternative model generates superior or inferior results.

In this study it was thus possible to evaluate the models in-sample and out-of-sample. 


\section{RESULTS ANALYSIS}

We ommited the results of the adequacy tests of the adjusted model, AICc, and the p-value of the tests carried out for different lags in each stock (Ljung-Box test standardized residuals and squared standardized residuals, ARCH test). We chose the models with the best (lowest) AICc value. We analyzed the behavior of the coefficients of each stock ( $m u$, AR1, MA1, alpha and beta - with and without lags, Gamma Vexog, Skew, and Shape), using 5\% significance ( $\mathrm{p}$-value $>0.05$ ) as a reference.

Again, due to the page limit, we chose to carry out a general analysis of all stocks, ordered by those that had the highest and lowest variations in the non-regular trading hours. We calculated the daily mean of the absolute variation of the exogenous variables, that is, $\mathrm{AM}, \mathrm{OP}$, and OV. Table 5 indicates the absolute mean value of the variation for these three periods, respectively.

Table 5

Daily average variation of the exogenous variables

\begin{tabular}{|c|c|c|c|}
\hline & AM & OP & OV \\
\hline CSNA3 & 0.003548814 & 0.008745876 & 0.008873695 \\
\hline OIBR4 & 0.004211465 & 0.008800468 & 0.008755965 \\
\hline PETR4 & 0.002825213 & 0.008310654 & 0.008693282 \\
\hline SANB11 & 0.003836082 & 0.008177516 & 0.007839651 \\
\hline VALE5 & 0.002373105 & 0.00739494 & 0.007547827 \\
\hline GGBR4 & 0.003033502 & 0.007377315 & 0.007535473 \\
\hline TIMP3 & 0.003867277 & 0.008036907 & 0.00747945 \\
\hline ITUB4 & 0.002608262 & 0.007004393 & 0.006958666 \\
\hline CPLE6 & 0.003427863 & 0.007405181 & 0.006894102 \\
\hline FIBR3 & 0.003542756 & 0.007154832 & 0.0067755 \\
\hline BBDC4 & 0.002594722 & 0.006728224 & 0.006651544 \\
\hline SBSP3 & 0.003714428 & 0.006968218 & 0.006639699 \\
\hline EMBR3 & 0.003731118 & 0.007009767 & 0.006549214 \\
\hline CMIG4 & 0.003006004 & 0.006169636 & 0.006231121 \\
\hline BRFS3 & 0.003310456 & 0.006302612 & 0.006002672 \\
\hline CPFE3 & 0.003231528 & 0.006195274 & 0.005724897 \\
\hline VIVT4 & 0.002954537 & 0.005788055 & 0.005591866 \\
\hline UGPA3 & 0.002983965 & 0.005906725 & 0.005504156 \\
\hline PCAR4 & 0.002938879 & 0.005786827 & 0.005415152 \\
\hline ABEV3 & 0.002528768 & 0.004793972 & 0.004690389 \\
\hline
\end{tabular}

The variables are described in the text.

Source: Elaborated by the authors.

As observed in Table 5, the pre-opening period has a higher mean variation than the after-market period, suggesting that it is responsible for most of the variation of the total overnight period. The securities that present the highest mean variation in the non-regular hours were CSNA3, OIBR4, PETR4, SANB11, and VALE5, while those that present the lowest mean variation were ABEV3, PCAR4, UGPA3, VIVT4, and CPFE3. Barclay and Hendershott (2004) indicate that the variation of the non-regular periods is important only when there is sufficient movement for this. Thus, it is believed that the arrival of important information in the after-market and pre-opening periods for modeling volatility occurs especially in the stocks that presented the highest mean daily variation.

Also evaluating the models in-sample, Table 6 indicates the models that presented the best (lowest) AICc information criterion for each one of the categories, whether these were without the exogenous variable, incorporating the after-market (AM) period, incorporating the pre-opening $(\mathrm{OP})$ period, or incorporating the total overnight $(\mathrm{OV})$ period. The models that presented the best criteria of them all are highlighted. 
Table 6

Best corrected Akaike (AICC) information criteria for the models of each stock

\begin{tabular}{|c|c|c|c|c|c|}
\hline & AICc & & & AICc & \\
\hline \multirow{4}{*}{ ABEV3 } & APARCH $(1,1)$ & -5.71159 & \multirow{4}{*}{ BBDC4 } & APARCH $(1,1)$ & -5.41311 \\
\hline & APARCH $(1,1)+$ AM & -5.70970 & & APARCH $(1,2)+$ AM & -5.42162 \\
\hline & APARCH $(2,2)+$ OP & -5.72134 & & APARCH $(1,2)+$ OP & -5.42163 \\
\hline & APARCH $(2,2)+$ OV & -5.72012 & & APARCH $(1,2)+$ OV & -5.42163 \\
\hline \multirow{4}{*}{ BRFS3 } & APARCH $(1,1)$ & -5.37863 & \multirow{4}{*}{ CMIG4 } & APARCH $(1,1)$ & -5.29872 \\
\hline & APARCH $(1,1)+$ AM & -5.37741 & & APARCH $(1,1)+$ AM & -5.29874 \\
\hline & APARCH $(1,1)+$ OP & -5.37741 & & APARCH $(1,2)+$ OP & -5.32857 \\
\hline & APARCH $(1,1)+$ OV & -5.37741 & & APARCH $(2,2)+$ OV & -5.33154 \\
\hline \multirow{4}{*}{ CPFE3 } & APARCH $(1,1)$ & -5.66059 & \multirow{4}{*}{ CPLE6 } & $\operatorname{APARCH}(1,1)$ & -5.32234 \\
\hline & APARCH $(1,2)+$ AM & -5.65720 & & APARCH $(1,1)+$ AM & -5.32034 \\
\hline & APARCH $(2,2)+$ OP & -5.65860 & & APARCH $(1,1)+$ OP & -5.32281 \\
\hline & APARCH $(2,2)+O V$ & -5.65969 & & APARCH $(1,1)+$ OV & -5.33485 \\
\hline \multirow{4}{*}{ CSNA3 } & APARCH $(1,1)$ & -4.74253 & \multirow{4}{*}{ EMBR3 } & APARCH $(1,1)$ & -5.08514 \\
\hline & APARCH $(1,1)+$ AM & -4.74532 & & APARCH $(1,2)+$ AM & -5.08201 \\
\hline & APARCH $(2,1)+$ OP & -4.75104 & & $\operatorname{APARCH}(1,1)+$ OP & -5.09151 \\
\hline & APARCH $(1,1)+$ OV & -4.75197 & & APARCH $(1,1)+$ OV & -5.09456 \\
\hline \multirow{4}{*}{ FIBR3 } & APARCH $(1,1)$ & -4.67232 & \multirow{4}{*}{ GGBR4 } & $\operatorname{APARCH}(1,1)$ & -4.91230 \\
\hline & APARCH $(1,1)+$ AM & -4.67038 & & APARCH $(2,2)+$ AM & -4.91280 \\
\hline & $\operatorname{APARCH}(1,1)+$ OP & -4.67037 & & APARCH $(1,2)+$ OP & -4.93230 \\
\hline & APARCH $(1,1)+$ OV & -4.67032 & & APARCH $(1,2)+$ OV & -4.93212 \\
\hline \multirow{4}{*}{ ITUB4 } & APARCH $(1,1)$ & -5.31292 & \multirow{4}{*}{ OIBR4 } & $\operatorname{APARCH}(1,2)$ & -4.58497 \\
\hline & $\operatorname{APARCH}(1,2)+\mathrm{AM}$ & -5.32008 & & APARCH $(1,2)+$ AM & -4.58314 \\
\hline & APARCH $(1,2)+$ OP & -5.31190 & & APARCH $(1,2)+$ OP & -4.60736 \\
\hline & APARCH $(2,2)+$ OV & -5.30970 & & APARCH $(1,2)+$ OV & -4.61311 \\
\hline \multirow{4}{*}{ PCAR4 } & APARCH $(1,1)$ & -5.34712 & \multirow{4}{*}{ PETR4 } & APARCH $(2,2)$ & -5.06764 \\
\hline & APARCH $(1,1)+$ AM & -5.34530 & & $\operatorname{APARCH}(2,2)+\mathrm{AM}$ & -5.06565 \\
\hline & APARCH $(1,1)+$ OP & -5.34532 & & APARCH $(2,1)+$ OP & -5.09839 \\
\hline & APARCH $(1,1)+$ OV & -5.34533 & & APARCH $(2,1)+$ OV & -5.10900 \\
\hline \multirow{4}{*}{ SANB11 } & APARCH $(1,1)$ & -5.10457 & \multirow{4}{*}{ SBSP3 } & APARCH $(1,1)$ & -5.11231 \\
\hline & APARCH $(1,1)+$ AM & -5.10262 & & $\operatorname{APARCH}(1,2)+\mathrm{AM}$ & -5.11720 \\
\hline & APARCH $(1,1)+$ OP & -5.10255 & & $\operatorname{APARCH}(1,2)+$ OP & -5.11810 \\
\hline & APARCH $(1,1)+$ OV & -5.10285 & & APARCH $(1,2)+$ OV & -5.12030 \\
\hline \multirow{4}{*}{ TIMP3 } & APARCH $(1,2)$ & -4.98892 & \multirow{4}{*}{ UGPA3 } & APARCH $(2,2)$ & -5.72721 \\
\hline & $\operatorname{APARCH}(2,2)+\mathrm{AM}$ & -4.98592 & & APARCH $(1,2)+A M$ & -5.74570 \\
\hline & APARCH $(2,2)+$ OP & -5.00678 & & $\operatorname{APARCH}(1,2)+$ OP & -5.73839 \\
\hline & APARCH $(2,2)+$ OV & -5.00448 & & APARCH $(1,2)+$ OV & -5.74565 \\
\hline \multirow{4}{*}{ VALE5 } & APARCH $(1,1)$ & -5.32292 & \multirow{4}{*}{ VIVT4 } & APARCH $(2,2)$ & -5.61880 \\
\hline & APARCH $(1,2)+$ AM & -5.32486 & & APARCH $(1,2)+$ AM & -5.62073 \\
\hline & APARCH $(1,1)+$ OP & -5.33919 & & APARCH $(1,2)+$ OP & -5.62728 \\
\hline & APARCH $(2,2)+O V$ & -5.34683 & & APARCH $(1,2)+$ OV & -5.62076 \\
\hline
\end{tabular}

The variables are described in the text.

Values in bold indicate the models that presented the best AICc out of all for that stock.

Source: Elaborated by the authors.

The results indicate that for the AICc information criteria the model without the exogenous variables is the best only for the BRFS3, CPFE3, FIBR3, PCAR4, and SANB11 stocks. It is worth noting that of these five companies only SANB11 presents a higher mean daily variation in the nonregular periods of the trading hours. This fact may be due to these companies not presenting superior results when the exogenous variables were incorporated.

For all the other stocks, at least one of the models that incorporate the exogenous variables presented superior results for the in-sample analysis. For the ITUB4 and UGPA3 stocks, the model that presented the best result of the sample was the one that incorporates the after-market period, indicating that for these stocks the trades that occur in this period are important for the conditional volatility estimation. For ABEV3, GGBR4, TIMP3, and VIVT4, the variation between the opening and closing price of the after-market period, that is, the information incorporated into the pre-opening period, shows the exogenous variable to be more important, since the OP 
model presented the best result in relation to the rest. For the other stocks, BBDC4, CMIG4, CPLE6, CSNA3, EMBR3, OIBR4, PETR4, SBSP3, and VALE5, the model that presented the best result was $\mathrm{OV}$, that is, the one that incorporates the total overnight period (variation of the opening price in relation to the closing price of the regular trading session of the previous day).

It is therefore found that when evaluating the AICc information criteria (in-sample analysis), the exogenous variables provided better-fitting models for most of the stocks. It is also worth noting that the pre-opening $(\mathrm{OP})$ and the total overnight (OV) periods appear to incorporate more information than the after-market period, which may be explained by the lower variation of the after period in relation to the others, as seen in Table 6, and corroborating the results found by Chen et al. (2012).
One noteworthy point is that the difference in the values of the criteria for the different models is small for most of the stocks. This is an indication that there is no unanimity regarding the impact of the exogenous variables. Therefore, other criteria need to be used to complement the study's analyses.

In order to summarize the results found in this research, Table 7 presents the main indicators both for the in-sample and out-of-sample model estimations. For the in-sample analysis, the models that stand out, when incorporating the exogenous variables, are those that presented superior results for the AICc criterion and those in which the coefficients of the exogenous variables were statistically significant. The criteria for the out-of-sample analysis indicate the models that presented superior results using the $\mathrm{R}^{2}$ of the $\mathrm{MZ}$ regression criterion and the estimation errors criteria.

Table 7

Summary of the results found in the research

\begin{tabular}{|c|c|c|c|c|c|c|c|c|c|c|c|c|c|c|c|}
\hline \multirow{2}{*}{ Stock } & \multicolumn{3}{|c|}{ In-sample AICc } & \multicolumn{3}{|c|}{ In-sample Coeff. } & \multicolumn{3}{|c|}{ Out-of-sample $\mathbf{R}^{2} \mathrm{MZ}$} & \multicolumn{3}{|c|}{ Out-of-sample errors } & \multicolumn{3}{|c|}{ Out-of-sample DM test } \\
\hline & AM & OP & OV & AM & OP & OV & AM & OP & OV & AM & OP & OV & AM & OP & OV \\
\hline ABEV4 & & $* *$ & $*$ & $*$ & $* * *$ & $* *$ & $*$ & $* *$ & * & $* *$ & $* * *$ & & + & + & \\
\hline BBDC4 & $*$ & $*$ & $* *$ & & & & & & & & & & - & & \\
\hline BRFS3 & & & & & & & $* *$ & $*$ & $*$ & & & & & & \\
\hline CMIG4 & * & * & ** & & $* * *$ & $* * *$ & $*$ & $* *$ & & $* * *$ & & & + & - & \\
\hline CPFE3 & & & & & & $*$ & & & & $*$ & & & & & \\
\hline CPLE6 & & * & ** & & $* * *$ & $* * *$ & * & $*$ & $* *$ & $* *$ & $* *$ & ** & & & \\
\hline CSNA3 & $*$ & * & ** & & * & & * & & $* *$ & $* *$ & $* *$ & $* * *$ & + & + & + \\
\hline EMBR3 & & $*$ & $* *$ & & & & & $*$ & $* *$ & $*$ & $*$ & $*$ & & & \\
\hline FIBR3 & & & & & & & $* *$ & $*$ & & $*$ & & & & & - \\
\hline GGBR4 & $*$ & $* *$ & $*$ & & & $* *$ & & $* *$ & & $* *$ & $* * *$ & $* *$ & & + & \\
\hline ITUB4 & $* *$ & & & & & & & & & $*$ & & & & & - \\
\hline OIBR4 & & $*$ & $* *$ & & $* * *$ & $* * *$ & $*$ & $* *$ & $*$ & & $*$ & & - & - & - \\
\hline \multicolumn{16}{|l|}{ PCAR4 } \\
\hline PETR4 & & $*$ & $* *$ & & $* * *$ & $* * *$ & $* *$ & & & & $*$ & $*$ & - & & \\
\hline SANB11 & & & & & & $* * *$ & $* *$ & & & $*$ & & & & - & \\
\hline SBSP3 & $*$ & $*$ & $* *$ & $* * *$ & $* * *$ & $* * *$ & $*$ & $*$ & $* *$ & $* *$ & $* *$ & $* *$ & + & + & + \\
\hline TIMP3 & & $* *$ & $*$ & & $* *$ & & & $* *$ & & $* *$ & $* *$ & & & & \\
\hline UGPA3 & $* *$ & $*$ & $*$ & & & & * & $*$ & $* *$ & $* *$ & $* *$ & $* *$ & & + & \\
\hline VALE5 & $*$ & $*$ & $* *$ & & $* * *$ & $* *$ & $* *$ & & & & $*$ & & - & & - \\
\hline VIVT4 & $*$ & $* *$ & * & & $* * *$ & & & $* *$ & $*$ & $* * *$ & & & & & \\
\hline Total & 9 & 14 & 14 & 2 & 10 & 10 & 12 & 12 & 9 & 14 & 11 & 7 & 4 & 5 & 2 \\
\hline The best & 2 & 4 & 9 & & & & 5 & 6 & 5 & & & & & & \\
\hline
\end{tabular}

Notes: For the in-sample corrected Akaike (AICC) information criterion: ${ }^{*}=$ models in which the exogenous variable was superior to the traditional model; ${ }^{* *}=$ model that presented the best result of them all.

For in-sample coeff. ${ }^{*}, * *, * * *=$ statistical significance of the coefficient of the exogenous variable at the level of 10,5, and $1 \%$, respectively.

For out-of-sample Mincer-Zarnowitz (MZ) $R^{2}$ criteria: * = models in which the exogenous variable presented a superior $R^{2}$ to the traditional model; ${ }^{* *}=$ model that presented the best result of them all.

For out-of-sample errors criteria: * = models in which at least one of the two criteria (root mean squared error - RMSE - and mean absolute percentage error - MAPE) presented a superior result to the traditional model; ${ }^{* *}=$ models in which both criteria were superior to the traditional model; ${ }^{* *}=$ models that presented the best results for both criteria out of all the models.

For the Diebold Mariano (DM) test: + = statistically significant and superior models; - = statistically significant and inferior models (level of $5 \%$ significance).

The variables are described in the text.

Source: Elaborated by the authors. 
Table 7 presents, in summarized form, the main results of this research. It is noteworthy that, for all the criteria, the models that incorporate non-regular trading hours presented interesting results. The criteria used for the in-sample evaluation indicate that the pre-opening and total overnight periods present superior results to the models that incorporate the after-market period, since the coefficient of the exogenous variable was only significant for two stocks for this period and for 10 stocks for the other two. In addition, the AICc criterion presented the best result for the two periods, especially for the total overnight period, in which nine times it presented a better result in relation to the other models.

The out-of-sample analysis indicates similar general numbers for the models incorporating the exogenous variables. For the $\mathrm{R}^{2}$ criterion, the models that incorporated the $\mathrm{AM}$ and $\mathrm{OP}$ periods presented superior results to the traditional one 12 times, while the models that incorporated the OV variable presented superior results nine times. In addition, each one of them was the best of all, five, six, and five times, respectively. The final criterion that evaluates the estimation errors (how far the estimated value is from the realized values) indicated that incorporating the AM period improved the results 14 times for at least one of the criteria, incorporating the OP period improved them 11 times, and incorporating the OV period improved them seven times. This result to a certain extent contradicts those of the in-sample analysis. However, it is worth noting that the impact of the superior results from incorporating the AM period, which was lower than the impact of incorporating the OP period, indicates the greater relevance of the latter in relation to the former.

Finally, with the aim of carrying out a more rigorous analysis, the Diebold Mariano test indicates the alternative models that presented statistically different forecasting errors from the traditional models. The test indicates that four stocks (ABEV3, CMIG4, CSNA3, and SBSP3), for the models that incorporated the AM variable, had superior results to the traditional ones, while four had inferior results and 12 had the null hypothesis that the forecasting errors are the same; therefore, it is not rejected. For the models that incorporated the $\mathrm{OP}$ variable, five stocks (ABEV3, CSNA3, GGBR4, SBSP3, and UGPA3) had superior results, while three had inferior results and $12 \mathrm{had}$ the null hypothesis that the forecasting errors are the same; thus, it is not rejected. For the models that incorporated the OV variable, only two models had superior results (CSNA3 and SBSP3), while four had negative results and another 14 had the null hypothesis that the forecasting errors are the same; therefore, it is not rejected.

The results found in the study do not enable conclusions to be made regarding a single model for all companies, but they do enable it to be affirmed that the non-regular trading periods incorporate relevant information for the conditional volatility estimation models for some of the stocks, thus corroborating the results from Gallo and Pacini (1998) and Taylor (2007) for the international market. The studies of the Brazilian market by Souza (2004) and Accioly and Mendes (2015) did not reach a unique conclusion for all stocks; however, both indicate the significance of the overnight period in the conditional volatility modeling for most cases, as in this study.

Moreover, the results are similar to those found by Chen et al. (2012), in which they evaluate the 30 most liquid stocks on the Nasdaq and conclude that the nonregular trading period incorporates relevant information for the conditional volatility models for most companies, but not for all. In addition, the authors also showed that the pre-opening period incorporates more information than the others when incorporated into the GARCHfamily models.

\section{FINAL REMARKS AND CONCLUSIONS}

Based on the assumption that relevant information for forecasting volatility comes to the market in non-regular trading hours, this study evaluated how the after-market and pre-opening periods affect the estimation of the conditional volatility of Brazilian companies listed on the BM\&FBovespa and belonging to the BR Titans 20 index.

Using an analysis not previously carried out in Brazil, we evaluated the non-regular trading period subdivided into two, in order to identify relevant information for estimating volatility. In addition, we used the realized (perceived) volatility measure as a proxy for the volatility of a day, so as to compare between estimated and realized values. This has still barely been explored in Brazil, due to the need for high frequency data and the difficulty in working with them.

In both the in-sample and out-of-sample analyses, there is no unanimity with relation to the best model. For the great majority of the stocks, using the different criteria, the models that incorporated the exogenous variables exceeded the traditional model, signaling that relevant information for forecasting volatility one day ahead arrives during the non-regular trading period. The 
traditional model, without incorporating the exogenous variables, was superior in the three evaluation criteria used only for two stocks. In addition to these, in another three stocks, despite the models incorporating the non-regular trading hours presenting superior results in some criteria, the improvement was very small or insignificant.

The results found in this study were not conclusive for a single model being superior to the others, but they enable us to affirm that non-regular trading hours incorporate relevant information into the conditional volatility estimation models for a sizeable portion of the stocks, thus corroborating with the international studies by Gallo and Pacini (1998) and Taylor (2007) and the studies of the Brazilian market, such as those by Souza (2004) and Accioly and Mendes (2015). In addition, the results indicate that the pre-opening period has a greater impact on the non-regular period as a whole (total overnight) and is more significant for the modeling of conditional volatility, which is a similar conclusion to those of Chen et al. (2012).

In finding the importance of the non-regular trading period for estimating the conditional volatility of stocks, this study offers relevant information for investment agents to be able to refine volatility forecasting models and, consequently, obtain better results in the pricing of derivatives, in risk management (value at risk - VaR calculation), and in the composition and optimization of investment portfolios.
We suggest that the causes of these results may derive from three origins: (i) cointregration between markets, since during non-regular trading hours in Brazil, other markets are functioning and can have an impact on the Brazilian one; (ii) relevant information being released in this period, according to the current legislation; and (iii) the possibility of informational asymmetry, in which traders with privileged information issue buy and sell orders in non-regular trading hours and this information is absorbed by the market during the first hours of the regular session, as is also suggested by Chen et al. (2012).

One limitation of this study is that the Brazilian capital market still suffers many fluctuations and sometimes the variation of non-regular trading hours can be very low. For future studies, we suggest an analysis of the impact of the non-regular trading period in different intraday periods of the regular trading session, especially in the first hours of trading, in this case not only evaluating the impact on volatility, but also on return itself. Another suggestion is the analysis of other variables as a proxy for the observed volatility of a day to compare the results found using realized volatility as a proxy. As a way of confirming/comparing the results found in this study, we also suggest carrying out an analysis with stochastic volatility models, instead of conditional volatility models. In addition, a qualitative analysis of the market makers and operators of non-regular trading hours could generate insights and interesting answers in future studies.

\section{REFERENCES}

Accioly, V. B., \& Mendes, B. V. M. (2015). EGARCH-RR: realized ranges explaining EGARCH volatilities. Relatório COPPEAD, 416, 1-23.

Akaike, H. (1974). A new look at the statistical model identification. IEEE transactions on automatic control, 19(6), 716-723.

Andersen, T. G., \& Bollerslev, T. (1998). Answering the skeptics: yes, standard volatility models do provide accurate forecasts. International Economic Review, 39(4), 885-905.

Andersen, T. G., Bollerslev, T., Diebold, F. X., \& Ebens, H. (2001a). The distribution of realized stock return volatility. Journal of Financial Economics, 61(1), 43-76.

Andersen, T. G., Bollerslev, T., Diebold, F. X., \& Labys, P. (2001b). Modeling and forecasting realized volatility. National Bureau of Economic Research, 71(2), 579-625.

Andersen, T. G., Bollerslev, T., Diebold, F. X., \& Labys, P. (2001c). The distribution of realized exchange rate volatility. Journal of the American Statistical Association, 96(453), 42-55.

Barclay, M. J., \& Hendershott, T. (2003). Price discovery and trading after hours. The Review of Financial Studies, 16(4), 1041-1073.
Barclay, M. J., \& Hendershott, T. (2004). Liquidity externalities and adverse selection: evidence from trading after hours. The Journal of Finance, 59(2), 681-710.

Bolsa de Valores, Mercadorias e Futuros de São Paulo. (2014). Manual de Procedimentos Operacionais do Segmento Bovespa: Ações, Futuros e Derivativos de Ações. Retrieved from http://www. bmfbovespa.com.br/lumis/portal/file/fileDownload. jsp?fileId=8AA8D0976075EB9901607A6ACDE8352E.

Bollerslev, T. (1986). Generalized autoregressive conditional heteroskedasticity. Journal of Econometrics, 31(3), 307-327.

Bollerslev, T., \& Wright, J. H. (2001). High-frequency data, frequency domain inference, and volatility forecasting. The Review of Economics and Statistics, 83(4), 596-602.

Burnham, K. P., \& Anderson, D. R. (2004). Multimodel inference: understanding AIC and BIC in model selection. Sociological Methods \& Research, 33(2), 261-304.

Cavaleri, R., \& Ribeiro, E. P. (2011). Combinação de previsões de volatilidade: um estudo. Revista Economia, 12(2), 239-261.

Ceretta, P. S., \& Costa, N. C. (2001). Particularidades do mercado financeiro latino-americano. Revista de Administração de Empresas, 41(2), 72-77. 
Chen, C. H., Yu, W. C., \& Zivot, E. (2012). Predicting stock volatility using after-hours information: evidence from the Nasdaq actively traded stocks. International Journal of Forecasting, 28(2), 366-383.

Comissão de Valores Mobiliários. (2002). Instrução CVM 358, de 3 de janeiro de 2002. This describes the disclosure and use of information about relevant acts and facts related to open companies, provides rules for the disclosure of information in the trading of securities and in the acquisition of a significant amount of stocks issued by open companies, establishes limits and conditions for the trading of open companies' stocks while a relevant fact has not been disclosed to the market, revokes CVM Instruction no. 31, of February $8^{\text {th }}$ of 1984 , CVM Instruction no. 69 , of September $8^{\text {th }}$ of 1987 , art. 3 of CVM Instruction no. 229 , of January $16^{\text {th }}$ of 1995 , the single paragraph of art. 13 of CVM Instruction no. 202, of December $6^{\text {th }}$ of 1993 , and arts. 3 to 11 of CVM Instruction no. 299, of February $9^{\text {th }}$ of 1999 , and sets out other arrangements. Retrieved from http://www.cvm.gov.br/export/sites/cvm/ legislacao/instrucoes/anexos/300/inst358.pdf.

Cumby, R., Figlewski, S., \& Hasbrouck, J. (1993). Forecasting volatilities and correlations with EGARCH models. The Journal of Derivatives, 1(2), 51-63.

Diebold, F. X., \& Mariano, R. (1995). Comparing predictive accuracy. Journal of Business and Economic Statistics, 13(3), 253-265.

Ding, Z., Granger, C. W., \& Engle, R. F. (1993). A long memory property of stock market returns and a new model. Journal of Empirical Finance, 1(1), 83-106.

Engle, R. F. (1982). Autoregressive conditional heteroscedasticity with estimates of the variance of United Kingdom inflation. Econometrica, 50(4), 987-1007.

Figlewski, S. (1997). Forecasting volatility. Financial Markets, Institutions and Instruments, 6(1), 1-88.

Gaio, L. E., Pessanha, G. R. G., Oliveira, D. R. de, \& de Ázara, L. N. (2007). Análise da volatilidade do índice Bovespa: um estudo empírico utilizando modelos da classe ARCH. Contextus, 5(1), 7-16.

Galdi, F. C., \& Pereira, L. M. (2007). Valor em Risco (VaR) utilizando modelos de previsão de volatilidade: EWMA, GARCH e Volatilidade Estocástica. Brazilian Business Review, 4(1), 74-95.

Gallo, G. M., \& Pacini, B. (1998). Early news is good news: the effects of market opening on market volatility. Studies in Nonlinear Dynamics \& Econometrics, 2(4), 115-131.

Giot, P., \& Laurent, S. (2004). Modelling daily value-at-risk using realized volatility and ARCH type models. Journal of Empirical Finance, 11(3), 379-398.

Hurvich, C. M., \& Tsai, C. L. (1993). A corrected Akaike information criterion for vector autoregressive model selection. Journal of Time Series Analysis, 14(3), 271-279.

Jorion, P. (1995). Predicting volatility in the foreign exchange market. The Journal of Finance, 50(2), 507-528.
Ljung, G. M., \& Box, G. E. (1978). On a measure of lack of fit in time series models. Biometrika, 65(2), 297-303.

Martens, M. (2002). Measuring and forecasting S\&P 500 indexfutures volatility using high-frequency data. Journal of Futures Markets, 22(6), 497-518.

Milach, F. T. (2010). Estimação da volatilidade: uma aplicação utilizando dados intradiários (Master's Dissertation). Escola de Administração, Universidade Federal do Rio Grande do Sul, Porto Alegre.

Mincer, J. A., \& Zarnowitz, V. (1969). The evaluation of economic forecasts. In: Economic forecasts and expectations: analysis of forecasting behavior and performance. Cambridge, MA: National Bureau of Economic Research.

Moreira, J. M. D. S., \& Lemgruber, E. F. (2004). O uso de dados de alta frequência na estimação da volatilidade e do valor em risco para o IBOVESPA. Revista Brasileira de Economia, 58(1), 100-120.

Mota, B. D. S., \& Fernandes, M. (2004). Desempenho de estimadores de volatilidade na bolsa de valores de São Paulo. Revista Brasileira de Economia, 58(3), 429-448.

$\mathrm{Ng}$, H. S., \& Lam, K. P. (2006). How does the sample size affect GARCH model? [Working Paper]. Department of Systems Engineering and Engineering Management, Chinese University of Hong Kong.

Nicolau, J. (2012). Modelação de séries temporais financeiras. Coimbra: Almedina. Coleção Econômicas II, n. 18.

Oomen, R. C. A. (2001). Using high frequency stock market index data to calculate, model \& forecast realized return variance [Discussion Paper]. European University, Economics.

Reis, D. L. P. E. (2011). Análise de desempenho de indicadores de volatilidade (Master's Dissertation). Faculdade de Economia e Administração, Universidade Federal de Juiz de Fora, Juiz de Fora.

Silva, C. A. G. (2009). Modelagem de estimação da volatilidade do retorno das ações brasileiras: os casos da Petrobrás e Vale. Cadernos do IME-Série Estatística, 26(1), 5-28.

Silva, J. C. (2002). Estimação do valor em risco usando informação intradiária (Master's Dissertation). Escola de Administração de Empresas, Fundação Getúlio Vargas, Rio de Janeiro.

Souza, M. N. C. (2004). Redução da persistência de volatilidade nos modelos GARCH para cálculo do valor em risco no mercado brasileiro (Master's Dissertation). Instituto Coppead de Administração, Universidade Federal do Rio de Janeiro, Rio de Janeiro.

Taylor, N. (2007). A note on the importance of overnight information in risk management models. Journal of Banking \& Finance, 31(1), 161-180.

Tsay, R. S. (2010). Analysis of financial time series. New Jersey: Wiley. Series in Probability and Statistics.

Zivot, E. (2009). Practical issues in the analysis of univariate GARCH models. In: Handbook of financial time series. Heidelberg: Springer. 